\title{
2-Dimensional Electrical Resistivity Technique for Locating Buried Materials and Characterizing the Depth to Basement Rock at Owo, Southwest, Nigeria
}

\author{
OLANEGAN Paul Oluwasegun, FASUNLA Olukayode Michael
}

\begin{abstract}
A Wenner array electrode configuration was employed to collect apparent resistivity data over a profile line of length $24 \mathrm{~m}$ in order to characterize the depth to the weathered basement rock for geotechnical assessment and groundwater investigation at a location in Rufus Giwa Polytechnic, Owo, Ondo State. To ensure accuracy in the resistivity model interpretation, high resistive materials and low resistive materials were buried at pre-determined locations along the profile line. A multi-electrode Wenner array configuration was adopted using 49 electrodes, for a minimum electrode spacing of $0.5 \mathrm{~m}$ covering 8 datum levels and 176 sounding points. The RES2DInv program was used to invert the apparent resistivity data and the resistivity model interpreted show that while the location and depth of the buried materials are accurately mapped, the depth to the weathered layer is averagely $1 \mathrm{~m}$ thick from about $2.6 \mathrm{~m}$ deep to a depth of $3.6 \mathrm{~m}$ with resistivity of $362 \Omega$.m. The water table is encountered at a depth of $3.69 \mathrm{~m}$ which is the surface of the saturated weathered layer. The highest resistivity of $1283 \Omega$.m which accurately mapped the buried empty kegs confirms that the resistivity of enclosed air is higher than that of the soil layers and weathered rocks. The overburden thickness of the section is approximately $3.70 \mathrm{~m}$. The subsurface structures that can support construction works at the location fall within 0 to 18 horizontal position to a depth of $3.6 \mathrm{~m}$.
\end{abstract}

Index Terms - Buried materials, Depth to Basement Rock, 2D Electrical Resistivity, Owo.

\section{INTRODUCTION}

Electrical resistivity methods of geophysical prospecting are aimed at detecting the surface effect produced by electric current flow in the ground. Using electrical method, one may measure potentials, current and electromagnetic fields that occur naturally or are introduced artificially in the ground (Dobrin, 1976). Geophysical methods involve a response to some physical property of the surface. For geotechnical and environmental applications, the main purpose of applying geophysical method is to delineate some subsurface structure or other discreet target. To be able to resolve a target, there must be a sufficient physical contrast between the target and the surrounding matrix to cause a response in the measured signal. The use of twodimensional (2-D) electrical imaging/tomography surveys to map areas with moderately complex geology has become very popular in recent times (Griffiths and Barker 1993; Sk et al, 2018;). In comparison with the Vertical Electrical Soundings, this method gives a more accurate model of the subsurface because it estimates the resistivity changes in the vertical direction, as well as in the horizontal direction along

Olanegan Paul Oluwasegun, Department of Science Laboratory Technology (Physics with Electronics Unit), Faculty of Applied Sciences, Rufus Giwa Polytechnic, P.M.B. 1019, Owo, Ondo State, Nigeria, the survey line. (Aizebeokhai, 2010). Metwaly and Alfouzan (2013) engaged 2-D geo-electrical resistivity as a costeffective solution for investigating subsurface caves, voids and shallow weathered zones. The results are very useful to determine the extension of shallow weathered zones and to locate different cavities underneath them.

In Rufus Giwa Polytechnic, which falls within the basement complex of Southwestern Nigeria the subsurface geology can be characterized into four namely topsoil, coarse sandy clay consisting mainly of quartzite, the weathered layer and the hard basement rock. Geotechnical considerations that can be obtained from surface geophysical surface include the nature and properties of soil and rocks properties (Dahlin, 1996). The entire campus of Rufus Giwa Polytechnic has been undergoing serious construction and developmental projects lately therefore the contribution of geophysics towards proper understanding of the geologic structures of the area will be beneficial.

\section{DESCRIPTION OF THE STUDY AREA}

\section{A. Location and Geology}

Owo is the headquarters of Owo Local Government Area of Ondo State. It is located about 45 kilometers East of Akure, the Ondo State Capital. Owo lies on latitude $7^{0} 15^{\text {, }}$ North of the Equator and longitude $5^{0} 35^{\text {, East of }}$ Greenwich Meridian (Aribigbola and Omosulu, 2012). The town falls within the sub equatorial region characterized by a Monsoon climate.

Geologically, Owo belongs to the basement complex of South West, Nigeria, which is underlain by Precambrian rocks. The major rocks in the area are granite, charnockites, quarzites, granite gneisses and migmatite gneisses. The granite rocks which are member of the older granite suite occupy about $65 \%$ of the total area. The magmatite gneisses, being the oldest rocks in the Nigerian basement, are both litho- and tectonostratigraphically basal to all superjacent lithologies and orogenic events (Rahman, 1976).

Rufus Giwa Polytechnic, Owo lies geographically within the tropical rain forest belt of hot and wet equatorial climatic region characterized by alternating wet and dry climate seasons, which is strongly controlled by seasonal fluctuation in the rate of evaporation. The study area (Fig 1.0) has a gently undulating topography ranging from $297.0 \mathrm{~m}$ to $322.0 \mathrm{~m}$ above the sea level. It can be located on latitude $7^{0} 13^{\prime} 40.62^{\prime \prime}$ and longitude $5^{0} 33^{\prime} 21.74^{\prime \prime}$ (Figure 2.0)

\section{B. Climate and Hydrology}

The vegetation assumes various shades of green in the wet season and turns brown or pale in the dry season. Normally the thick vegetation cover helps to trap rainwater and prevent severe subsurface run-off which usually gives rise to high erosion and gullying. The presence of large 


\section{2-Dimensional Electrical Resistivity Technique for Locating Buried Materials and Characterizing the Depth to Basement Rock at Owo, Southwest, Nigeria}

vegetation in the area is of advantage in arresting the depletion of groundwater and reducing the rate of evapotranspiration. Groundwater occurrence in the study area is, not only a consequence of hydrologic and geologic events, but also of the climatic (rainfall) conditions.

\section{THEORY OF ELECTRICAL RESISTIVITY METHOD}

Electrical geophysical methods measures the distribution of electrical resistance in the subsurface by applying direct current to the ground (Robinson and Coruh, 1988) using four electrodes (current sources) and measuring the potential difference (voltage) between a second pair of electrodes (current receptors). The resistance data may be inverted to produce conductivity estimates. During resistivity survey, current is injected into the earth through a pair of current electrodes, and the potential difference is measured between $\mathrm{V}$ being the voltage across the end faces the current passed a pair of potential electrodes. The current and potential electrodes are generally arranged in a linear array. The common arrays include the dipole-dipole array, Schlumberger array and the Wenner array.

Generally electric current can be propagated in rocks and minerals in three ways electronic (ohmic), electrolytic and electric conduction. The ohmic conduction is the normal type of current flow in materials containing free electrons such as the metals. This occur in good conductors with resistivities ranging from $10 \mathrm{ohms}$ to 20 ohms (Herman, 2001). The electrical resistivity of a cylindrical solid of length $\mathrm{L}$ and cross-sectional area $\mathrm{A}$ having resistance between the end faces is given by

$$
\rho-\frac{R A}{L} \text { where } R=\frac{v}{I}
$$

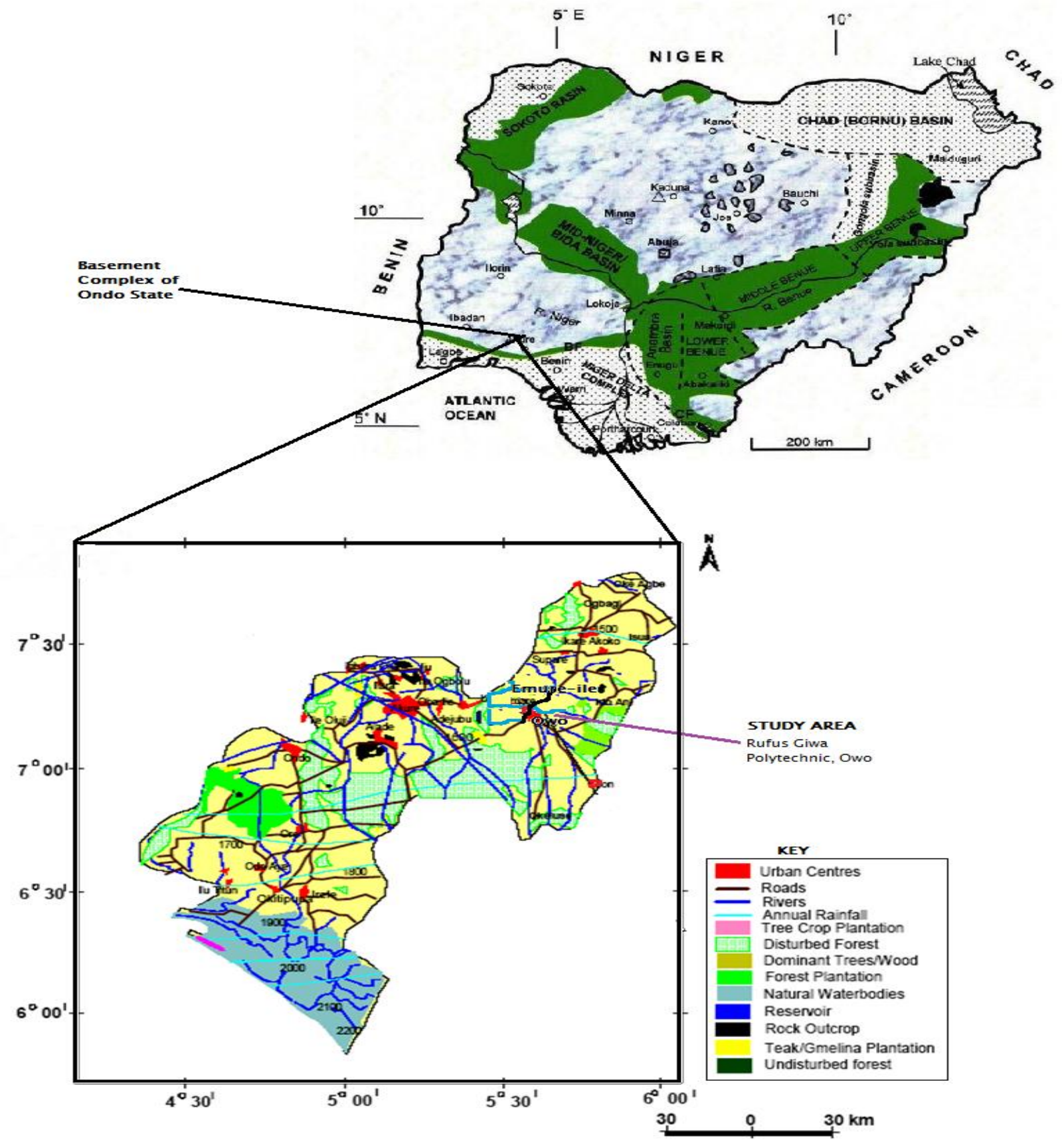

Figure 1.0: Geology of Nigeria and Location of the study area. (After Nigerian Geological Survey Agency, 2013) 
The reciprocal of resistivity is conductivity

i.e $\frac{1}{\rho}=\sigma=\frac{1}{R A}\left[\frac{1}{A}\right] /\left[\frac{V}{L}\right]=\frac{J}{E}$

Electrical conductivity of materials depends on the density and type of charges, mobility of the charges; frequency of the Inducing fields; and the temperature of the materials in some cases. However, in most sedimentary rocks, the salinity and the quantity of the pore-space fluids are the critical factors determining the resistivity of rocks more than the mineral grains forming the rock, while for dry rocks their conductivity is mainly dependent of the minerals in the rock (Telford et al., 1990). The bulk resistivity of rock formation according to Archie' law is

$$
\Phi=\operatorname{IF} \rho_{\mathrm{w}} \text {. }
$$

Where $\mathrm{F}=\mathrm{a} \Phi^{m}=$ formation factor

$$
\begin{aligned}
& \mathrm{I}=\mathrm{S}^{-\mathrm{n}}=\text { Resistivity index } \\
& \rho_{\mathrm{w}}=\text { Resistivity of pore fluid }
\end{aligned}
$$

$\Phi=$ Bulk porosity; $\mathrm{S}=$ Saturation of pore space; a, m, $\mathrm{n}=$ empirical constant with values satisfying different formation, a is generally $=1$, but $>1$ for joint porosity and $<1$ for intergranular porosity. $1.5<\mathrm{m}>2.6$ with the larger value associated with large pores. $S=1$ for formation below the water table and $<1$ for formation above the water table. The value $\mathrm{S}<\mathrm{I}$ may also indicate pores filled with gas or hydrocarbons.
For good saturation the resistivity index. $\mathrm{I}=\mathrm{b} \mathrm{S}^{-\mathrm{n}}$

Where $0.05<\mathrm{b}<0.5$ and $4<\mathrm{n}<$. the temperature effect on resistivity given as

$$
\rho_{1}=\frac{\rho_{\sigma}}{\mathrm{I}+\alpha t}
$$

Where $\alpha=$ temperature coefficient $=0.025^{\circ} \mathrm{e}^{-1}$

By the theory of potential field, the electric potential, due to a point source (i.e a source with radial symmetry), such as a current electrode embedded in an isotopic, homogenous medium is given as

$$
V=\frac{I \rho}{2 \pi r}
$$

Where $\rho=$ bulk resistivity

With two current electrodes embedded in a similar medium, the potential difference between two potential electrode, $\mathrm{M}, \mathrm{N}$ is

$$
\Delta \mathrm{V}=\frac{\mathrm{I} \rho}{2 \pi}\left\{\frac{1}{A M}+\frac{1}{B N}-\frac{1}{A N}-\frac{1}{B M}\right\}
$$

Such that the resistivity $\rho=$ of the medium is

$$
\rho=\frac{\Delta V}{I}\left\{\frac{2 \mu}{\frac{1}{A M}+\frac{1}{B N}-\frac{1}{A N}-\frac{1}{B M}}\right\}
$$

where $\mathrm{K}=$ geometric factor depends on the electrode configuration.

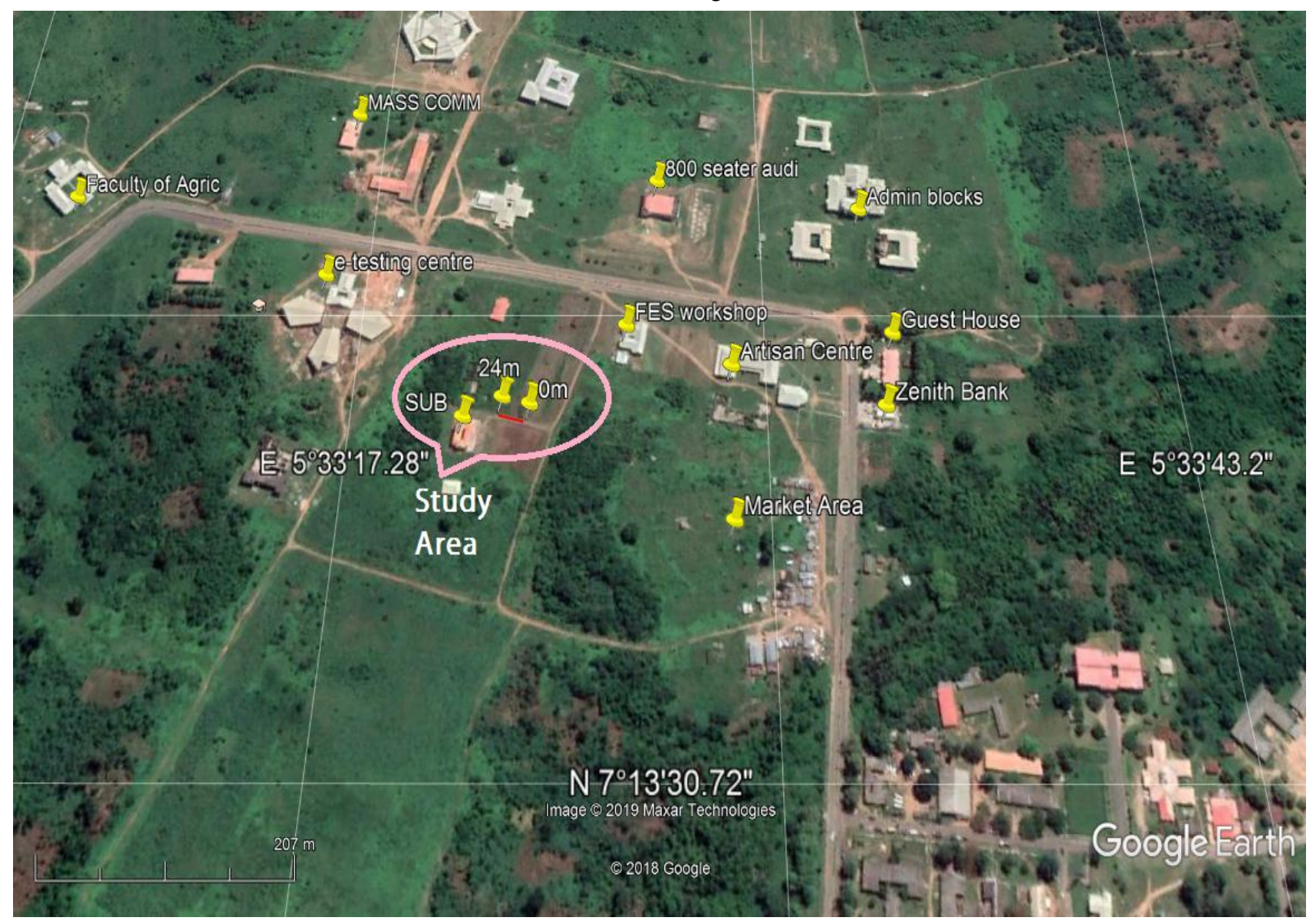

Figure 2.0: Satellite location of the study area (Google Maps, 2019) 


\section{2-Dimensional Electrical Resistivity Technique for Locating Buried Materials and Characterizing the Depth to Basement Rock at Owo, Southwest, Nigeria}

The basis of the electrical resistivity method is that when current is passed into the ground through electrode in the ground surface, any variation in the conductivity of subsurface layers alters the current flow path within the earth. This in turn affects the electric potential distribution at the surface. Hence by measuring the variation of the electric potential made at the surface information about the subsurface conducting earth materials can be obtained. The variation in the electric potential depends on the size, location, shape and resistivity of the causative materials.

The SUB area of Rufus Giwa Polytechnic, Owo was chosen so that for good accessibility to the site where there would not be disturbance during data acquisition. The area has also been identified from previous work as promising for groundwater potential having shallow aquifer so this research could also validate that finding (Olanegan, 2018; Falowo et al., 2015). The profile line of length $24 \mathrm{~m}$ was located astride the SUG Building as shown in Figure 2. Also, along the profile line, high resistivity materials and low resistivity materials were buried at specific points which will act as the targets which the imaging result would locate (Fig. 3.0). The low resistivity materials were metals plates majorly steel cans while the high resistive materials were constituted by three (3) empty kegs each of 25-litre capacity.

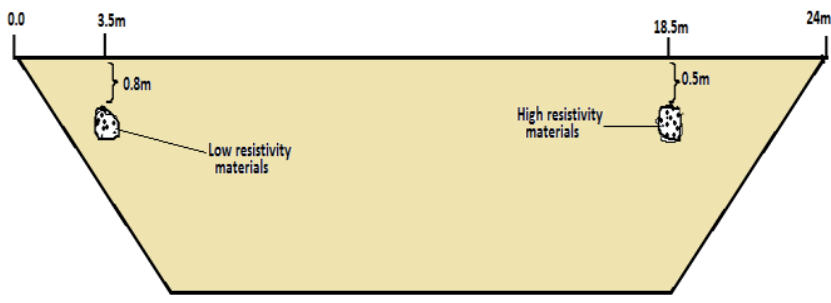

Figure 3.0: Location and depth of buried materials along the profile line

\section{FIELD PROCEDURE}

The basic equipment used are four non-polarizable electrodes: two current and two potential electrodes. For goods contact with the earth some water or salt solution is often poured on the ground around the electrodes. The R-50 resistance meter forms the most important equipment on the field survey. This is a power source for low frequency alternating current or direct current source; potentiometer or multi-voltmeter, presented in the form of resistivity meter (terrameter). This equipment can send current through the earth as low as 40mA. Other accessories used were hammers; four reels of insulated conductor cables and measuring tapes. In order to minimize errors in the field, the spread of the electrodes were maintained on a fairly straight line and station location was chosen at a flat area so as to avoid the effect of topography on the measurement.

For a 49-electrode multi-electrode array adopted for the work, a maximum of eight datum levels can be occupied while the maximum a-spacing would be " $8 \mathrm{a}$ ". With a profile length of $24.0 \mathrm{~m}, \mathrm{Ze}=24 \mathrm{~m} \times 0.173=4.152$, which is the maximum depth of investigation. Having marked the electrode positions, the electrodes are laid in a straight line with an a-spacing of $1 \mathrm{~m}$ between two consecutive electrodes and the cables connected to the first four electrodes, where $\mathrm{C} 1$ and $\mathrm{C} 2$ are current electrodes while $\mathrm{P} 1$ and $\mathrm{P} 2$ are potential electrodes. After taking the first reading station 1, the cables are moved in a leap-frog manner to the next position being electrodes 2, 3, 4, and 5 for the second station reading. The process is continued until station 43 for $a=1 \mathrm{~m}$ (Figure 4.0). For station 44, electrode spacing of $2 \mathrm{a}$ is used until station 83 has been reached. This process was taken for electrode spacings 3a, 4a, 5a, 6a, 7a and 8a which means that for the 49 electrode Wenner-alpha array used, the profile line requires that a total of 176 reading were taken. A recording table was designed to accommodate the recording; which requires that the $\mathrm{X}$-location of the resistivity reading in the pseudosection and electrode spacing must be specified for each reading. The apparent resistivities are calculated from the resistance data obtained and these were entered in a text file manually for computer processing.

The RES2DINV program used in the processing of 2Dresistivity imaging data displayed the output individually in three pseudosections (Loke, 2004). The first pseudosection is a contouring plot of the measured apparent resistivity values input into the program. The second pseudosection which is a contour of the calculated apparent resistivity values is compared with the measured apparent resistivity field data to develop the inverse model section. The inverse model resistivity section is the third psuedosection presented in the result, being the approximate true resistivity values of the subsurface. This inverted section will be used for the interpretation of the profiles (Fig 5.0).

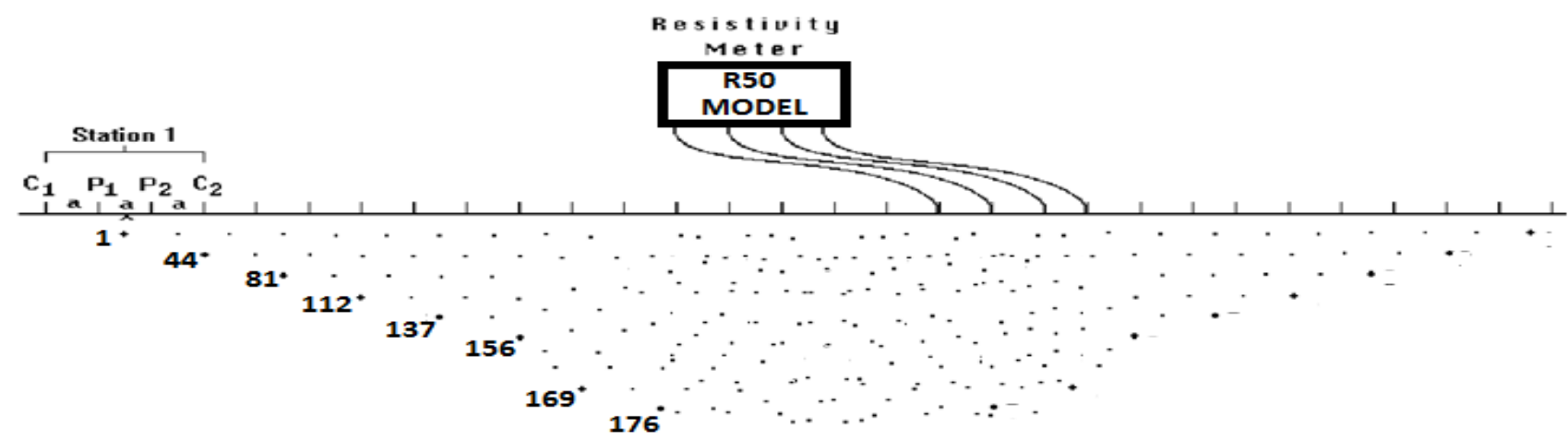

Figure 4.0: Electrodes arrangement for the multi-electrode array used for the profile line 
The Absolute RMS error of $2.2 \%$ is observed between the measured apparent resistivity data and the calculated apparent resistivity data which the program (RES2DINV) uses in generating the model. Very low RMS error indicates accuracy in the interpretation and how close to reality the measured data are. The inverse model has resistivity ranging from $<200 \Omega \mathrm{m}$ to about $1283 \Omega \mathrm{m}$. The depth covered by the model is $4.31 \mathrm{~m}$.
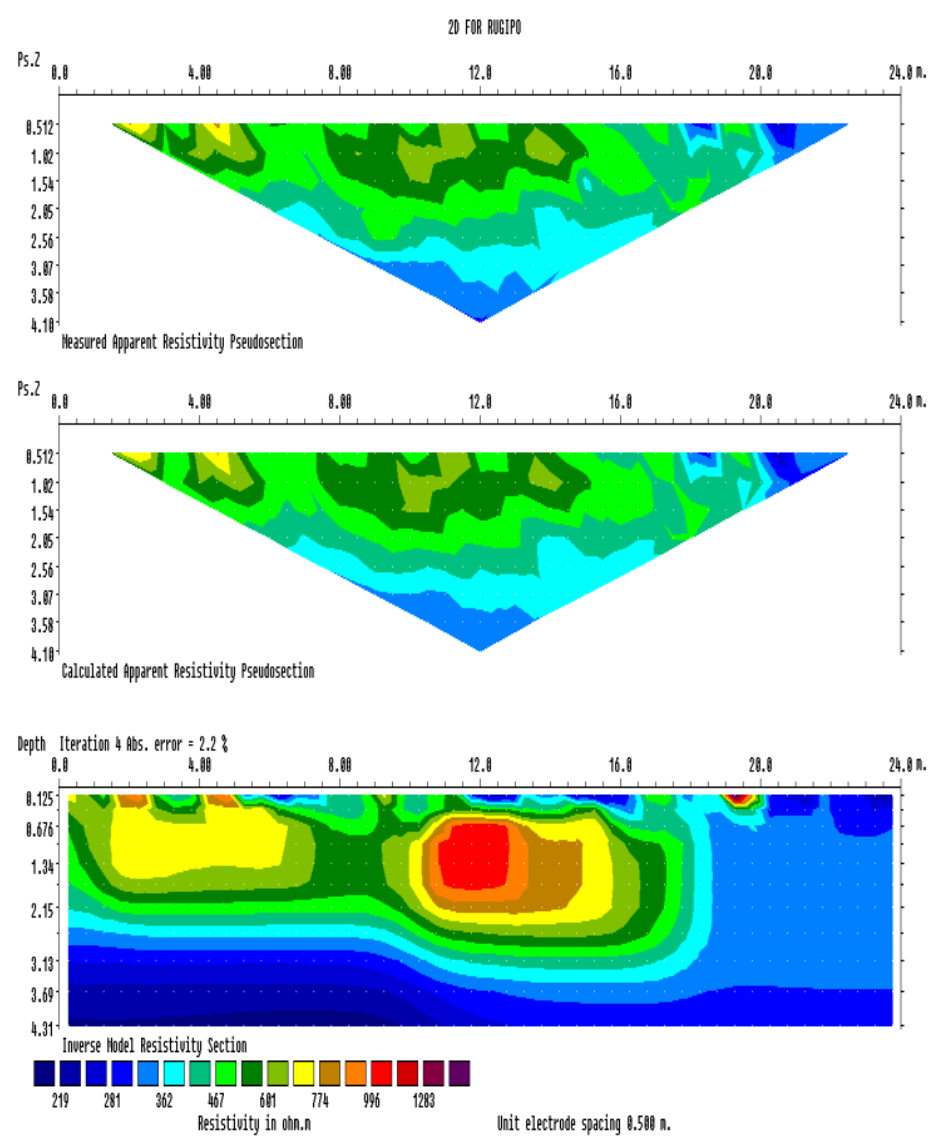

Figure 5.0: Result of the processed data, presented as three pseudo-sections representing the measures apparent resistivity pseudo-section, the calculated apparent resistivity pseudo-section and the inverse model resistivity section.

\section{INTERPRETATION AND RESULTS}

In the interpreted model (Figure 6.0), the resistivity ranges from about the lowest resistivity of about $120 \Omega \mathrm{m}$ to the highest resistivity of about $1283 \Omega \mathrm{m}$. From $0 \mathrm{~m}$ to $18 \mathrm{~m}$ horizontal positions along the profile line, resistivity increases steadily from the surface up to a depth of about $1.34 \mathrm{~m}$. Thereafter it undergoes a reducing trend in resistivity as the depth increases. The topsoil layer could shows that that the natural soil layers occurred up to about $2.2 \mathrm{~m}$ depth and it shows a. A very low resistive layers which is interpreted as a water bearing zone can be found at a depth of about $3.9 \mathrm{~m}$. This is the adopted depth to the water table at the location and the geologic material is interpreted as a weathered basement rocks. The shallow layers $(0.7 \mathrm{~m}$ to $2.2 \mathrm{~m}$ deep) are part of the excavated and sand-filled sections of the developed SUB area. The fairly lower resistivity sections encountered at near-surface areas from $5.0 \mathrm{~m}$ to $23.0 \mathrm{~m}$ along the profile line are taken as due to the percolating rain water which fell on the day during the data acquisition.

Another anomalous section encountered, at $3.0 \mathrm{~m}$ to $4.0 \mathrm{~m}$ along the profile line, is accurately a low resistivity anomaly $(390 \Omega \mathrm{m})$ that represents the location of the buried metallic materials, $3.5 \mathrm{~m}$ from the $0.0 \mathrm{x}$-location. The depth to the metallic materials $(0.5 \mathrm{~m})$ is actually the depth to which it is located by the inverse model. The highest resistivity of $1300 \Omega \mathrm{m}$ is located as an anomaly at between $18.75 \mathrm{~m}$ and $20.0 \mathrm{~m}$ along the profile line covering a depth of $0.5 \mathrm{~m}$ to $0.9 \mathrm{~m}$. This anomalous resistivity is located within a resistivity zone of about $400 \Omega \mathrm{m}$. This high resistivity is accurately interpreted as due to the high resistive plastic voids that were buried at that point. This is an indication of the accuracy of the electrical resistivity technique in locating high resistive materials embedded in the earth. This implies that the resistivity of air is higher than that of the soil layers and weathered rocks. The overburden thickness of the section is approximately $3.70 \mathrm{~m}$. The subsurface structures that can support construction works at the location fall within 0 to 18 horizontal position to a depth of $3.6 \mathrm{~m}$

\section{DISCUSSION}

From this research work we can conclude that:

i the highest resistivity anomaly encountered at $19 \mathrm{~m}$ to $20.0 \mathrm{~m}$ along the profile line coincides with the location of the buried high resistivity materials (empty rubber kegs). Thus we can confirm that the resistivity of hollow or voids existing within the earth can be accurately mapped with 2D resistivity imaging.

ii the location of the low resistive materials buried along the profile line was equally mapped by the imaging inverse model result. The low resistivity anomaly mapped at that point was having a resistivity of $362 \Omega \mathrm{m}$ compared with the surrounding resistivity of about $774 \Omega \mathrm{m}$ to $996 \Omega \mathrm{m}$.

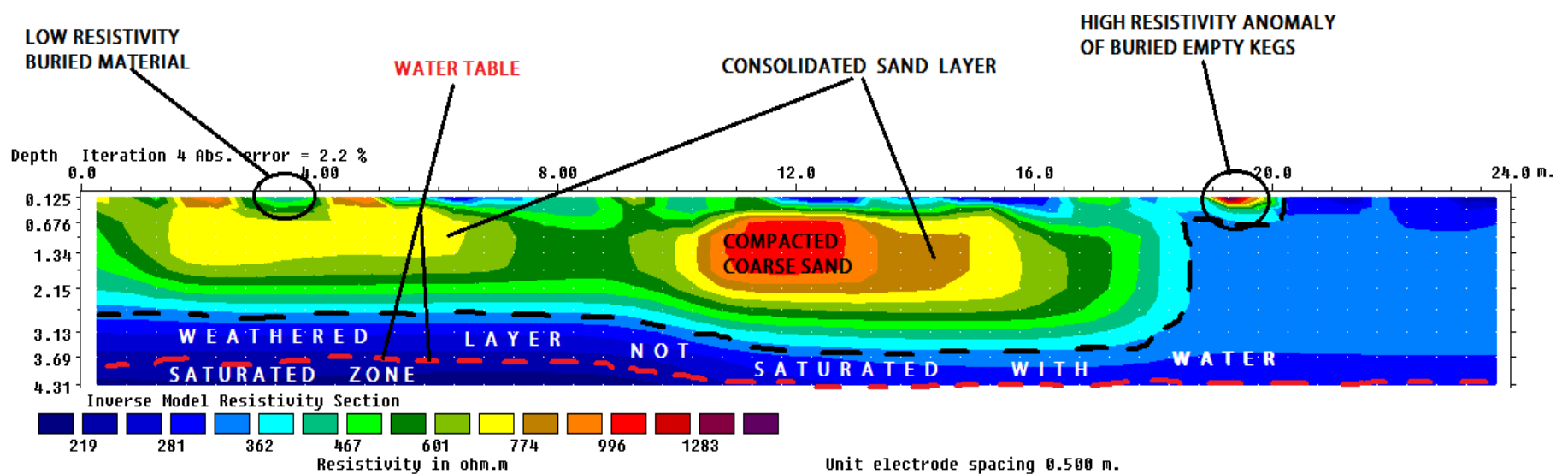

Figure 6.0: Interpreted model section of the profile line 


\section{2-Dimensional Electrical Resistivity Technique for Locating Buried Materials and Characterizing the Depth to Basement Rock at Owo, Southwest, Nigeria}

iii. the weathered basement rock which is not yet saturated with water begins at a depth of about $2.5 \mathrm{~m}$ with decreasing depths whose resistivity is controlled by the degree of water filling the pore spaces in the formation.

iv. the water table indicated by the low resistivity at a depth of about $3.69 \mathrm{~m}$ from the surface.

v. voids and spaces constitutes high resistivity in contrast with the earth formation, making it easy to be mapped by $2 \mathrm{D}$ resistivity imaging. This is the case with the buried empty kegs.

vi. the 2D resistivity imaging using the Wenner array is suitable for locating buried materials of distinct resistivities in the subsurface.

\section{CONCLUSION}

From the results of this work, the near-surface structures in the study area have a consolidated layered earth consisting of lateritic sandy with low permeability from the $0 \mathrm{~m}$ to $18 \mathrm{~m}$ along the profile line up to a depth of about $3.14 \mathrm{~m}$. The $18 \mathrm{~m}$ to $24 \mathrm{~m}$ sections are consisting of permeable coarse sands. The saturated zone is mapped at a depth of about 3.69 at the base of the section which is made of weathered basement rock. The weathered layer which is not saturated with water is found at a depth of $2.5 \mathrm{~m}$ up to $3.5 \mathrm{~m}$. The highest resistivity of $1283 \Omega$.m which accurately mapped the buried empty kegs confirms that the resistivity of air is higher than that of the soil layers and weathered rocks. The overburden thickness of the section is approximately $3.70 \mathrm{~m}$. The subsurface structures that can support construction works at the location fall within 0 to 18 horizontal position to a depth of $3.6 \mathrm{~m}$. At a depth of $2.5 \mathrm{~m}$ in the study area, the weathered basement rock can be encountered, which is able to support construction work or heavy structures. It is recommended that $2 \mathrm{D}$ resistivity imaging is a useful tool in locating buried metals and hollows spaces buried within the earth. Further work in the study area could expand the coverage of the data collected to higher depths in order to be able to map depth to the basement for clearer understanding of the subsurface structures.

\section{REFERENCES}

[1] Aizebeokhai, P. A. Olayinka, A. I. and Singh, V.S. (2010): 2D and 3D geoelectrical resistivity imaging: Theory and field design. Scientific Research and Essays. Vol. 5(23), pp. 3592-3605,

[2] Aribigbola, A and Omosule, S.B (2012): Water Supply Situation in Owo, Ondo State: Implication for the Sustainable City Development in Nigeria. Journal of Business and Sciences, Vol.1, No 3. Pp. 25-30

[3] Sk, M., Ramanujam, N., Champoil, V., Biswas, S.K., Rasool, Q.A. and Ojha, C. (2018): Identification of Groundwater in Hard Rock Terrain Using 2D Electrical Resistivity Tomography Imaging Technique: Securing Water Scarcity at the Time of Seasonal Rainfall Failure, South Andaman. International Journal of Geosciences, 9, 59-70.

[4] Dahlin T., (1996): 2D resistivity surveying for environmental and engineering applications, First Break, 14 (7), 275-283.

[5] Dobrin, M.B. (1976): Introduction to Geophysical Prospecting, M.C. Graw Hill Inc, New Jersey. pp. 26-30.

[6] Falowo, O. O., Daramola, A. O., Ojo, O. O. (2015): Geophysical Investigation for Groundwater Potential in Rufus Giwa Polytechnic Owo, Southwestern Nigeria. The International Journal of Engineering and Science (IJES). Vol. 4, Issue 11, Pp. 29-39.
[7] LLC.

Google Earth Pro (2019): Online Google Maps (C) Google Earth

[8] Griffiths, D. H. and Baker R. D., (1993): The use of multielectrodes resistivity imaging in gravel prospecting. Journal of Applied Geophysics, 49, 245-254.

[9] Herman, R. (2001): An Introduction to Electrical Resistivity in Geophysics. America Journal of Physics, Vol. 69 No. 9. Pp 943-952.

[10] Loke, M.H. (2004) RES2DINV version 3.8.9 - Geoelectrical Imaging 2-D and 3-D-Geotomo Software, - Rapid 2D resistivity and IP inversion using the least-squares method: Downloaded October 12, 2018

[11] Metwaly, M, and Alfouzan, F. (2013): Application of 2-D Geoelectrical Resistivity Tomography for Subsurface cavity Detection in the Eastern Part of Saudi Arabia. Geo-science Frontiers, Vol. 4 Pp. 69-476.

[12] Olanegan, P. O. (2018): Electrical Resistivity Technique For Delineating The Aquifer In Parts Of Rufus Giwa Polytechnic, Owo, Ondo State, Nigeria.." The International Journal of Engineering and Science (IJES) Vol 7.Issue 7 Pp. 79-87

[13] Rahman, M.A., (1976): Review of the Basement Geology of the South Western Nigeria. Journal of Mining and Geology.

[14] Robinson, E.S. and Coruh, C. (1988): Basic Exploration Geophysics. Wiley Publishers. New York.

[15] Telford, W.M., Geldart, L.P., Sheriff, R.E. (1990): Applied Geophysics (second edition). Cambridge University. 


\section{Author's Profile}

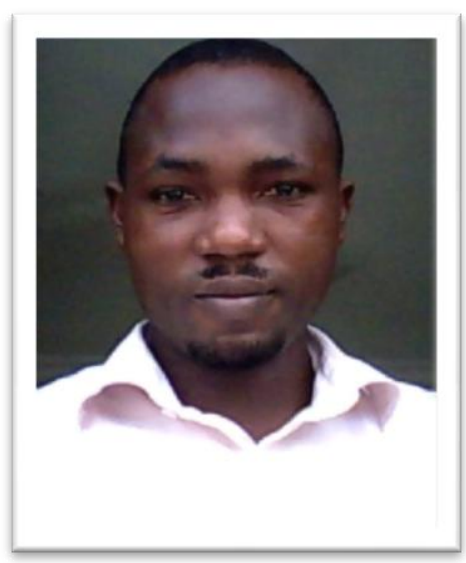

OLANEGAN, Paul Oluwasegun, had his Primary education at Wesley School II, Oko, Sagamu and Local Govt. Authority Primary School Sabo, Sagamu between 1983 and 1989. He also attended Methodist Comprehensive College, Sagamu, Ogun State (1989-1995), State College of Arts And Science, Sokoto (Jan.Dec., 1996), Usmanu Danfodiyo University, Sokoto, Sokoto State $(1998$ - 2000) and University of Port Harcourt, Port Harcourt, Rivers State (2004 - 2007). In December 2007, Olanegan Paul was awarded a Master of Science (M.Sc.) degree in Physics (Applied Geophysics) at University of Port Harcourt. Earlier, in 2000, he obtained a Bachelor of Science degree in Physics from Usmanu Danfodiyo University, Sokoto where he finished with a 2nd Class Upper Division. He has also obtained an A' Level result in 1996 and a Senior School Certificate in 1995.

$\mathrm{He}$ is currently a Lecturer at the Department of Science Laboratory Technology (Physics with Electronics Unit), Faculty of Applied Sciences, Rufus Giwa Polytechnic, Owo. Paul Olanegan had earlier worked as a Field Geophysicist in a geophysical consulting firm from 2008 to 2012 .

Professionally, Mr Paul Olanegan is a member of Nigerian Institute of Physics (NIP) as well as an Affiliate Member of Nigerian Mining and Geosciences Society (NMGS). He has scientific publications in both local and foreign journals to his credit.

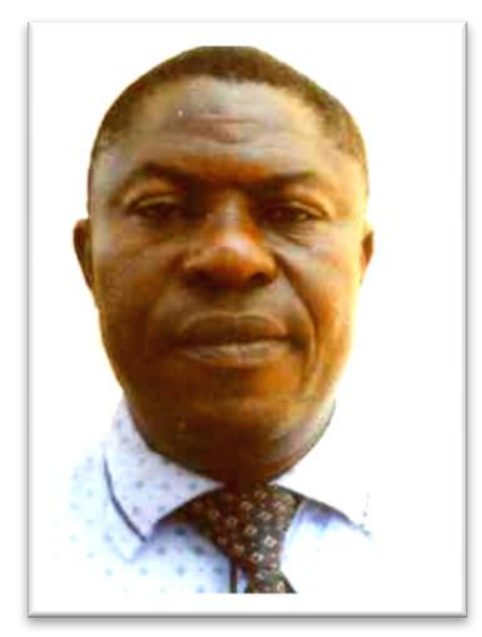

FASUNLA, Olukayode Michael, had his Primary education at St. Michael Anglican Primary School, Ilaramokin, Ondo State (1978). He also attended Oyemekun Grammar School, Akure, Ondo State (1978-1983), Federal University of Technology, Akure, Ondo State (1989-1995) and (2012-2018). In May 2018, Fasunla, Olukayode Michael was awarded a Master of Technology (M. Tech) degree in Physics (Electronics Measurement and Instrumentation) at Federal University of Technology, Akure. In 1995, he obtained his Bachelor of Technology (B. Tech) degree in Physics (Electronics) with Second Class Honours Lower Division and his General Certificate of Education (Ordinary Level) in 1984.

$\mathrm{He}$ is currently a lecturer at the Department of Science Laboratory Technology (Physics with Electronics unit), Faculty of Applied Sciences, Rufus Giwa Polytechnic, Owo.

Professionally, Fasunla, Olukayode Michael is a member of Nigerian Institute of Physics (NIP). He has scientific publications in both local and foreign journal to his credit. 